\title{
Performance of Temperature-Related Weather Index for Agricultural Insurance of Three Main Crops in China
}

\author{
Jing Zhang ${ }^{1} \cdot{\text { Zhao } \text { Zhang }^{1} \cdot \text { Fulu Tao }}^{2}$
}

Published online: 27 March 2017

(c) The Author(s) 2017. This article is an open access publication

\begin{abstract}
In this study, two categories of weather indexabsolute index and relative index - for chilling injury and heat damage of three main crops in China were assessed to identify insurable counties. First, correlations between selected weather indices and yield losses were examined for each county. If a correlation was significant, the county was categorized as "insurable" for the corresponding hazard or index. Second, the spatial distribution of insurable counties was characterized and finally, their correlation coefficients were analyzed at various spatial scales. The results show that the spatial patterns of insurable areas varied by categories of weather indices, crops, and hazards. Moreover, the weather indices based on relative threshold of temperature were more suitable for chilling injury in most regions, whereas the indices based on absolute threshold were more suitable for heat damage. The findings could help the Chinese government and insurance companies to design effective insurance products.
\end{abstract}

Keywords Chilling injury $\cdot$ China $\cdot$ Crop insurance $\cdot$ Heat damage . Weather index

Zhao Zhang

zhangzhao@bnu.edu.cn

Fulu Tao

taofl@igsnrr.ac.cn

1 State Key Laboratory of Earth Surface Processes and Resource Ecology/Key Laboratory of Environmental Change and Natural Hazards, Academy of Disaster Reduction and Emergency Management, Faculty of Geographical Science, Beijing Normal University, Beijing 100875, China

2 Institute of Geographical Sciences and Natural Resources Research, Chinese Academy of Sciences, Beijing 100101, China

\section{Introduction}

Climatic variables are key controls on crop growth and determine yields, contributing to yield variability in China by as much as 41,38 , and $62 \%$ for maize, rice, and wheat, respectively (Ray et al. 2015). Agro-meteorological hazards usually have significant negative impacts on crop yield, especially temperature-related hazards. For such hazards, the upper threshold temperature $\left(T_{\text {upper }}\right)$, optimum temperature $\left(T_{\text {opt }}\right)$, and lower threshold temperature $\left(T_{\text {lower }}\right)$ have generally been used to characterize crop response to ambient air temperature (Qian et al. 2010; Wang et al. 2014). Extreme low $\left(<T_{\text {lower }}\right)$ or high ( $>T_{\text {upper }}$ ) temperature events may have severe consequences for crop yields; these are called chilling injury or heat damage in the present study. With ongoing climate change, more frequent and intense extreme-temperature events will become a major challenge to crop production (Wang et al. 2014; Zhang et al. 2014a, b; Chen et al. 2016). More attention has been given to the meteorological causes of crop failure and effects of agro-meteorological hazards (Challinor et al. 2005; Lobell and Field 2007; Tao et al. 2008, 2013; Zhang et al. 2014a, b, 2016), but very few studies have focused on how to reduce corresponding economic losses from agro-meteorological hazards, especially in China.

As a measure of risk transfer for natural hazard-induced disasters, crop insurance may be used to shift various weather-related risks, and has become a prominent issue in many countries. However, studies and experience have concluded that traditional agricultural insurance is a very poor and unsustainable investment in lower income countries, owing to a preponderance of small farms and typical asymmetric information problems (Hazell 1992; Collier 


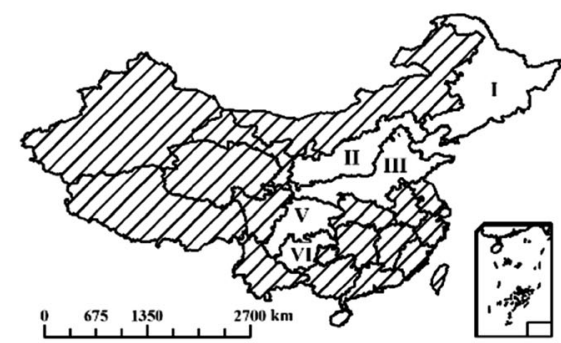

(a)

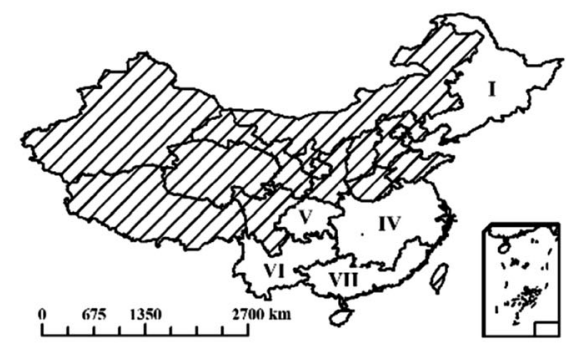

(b)

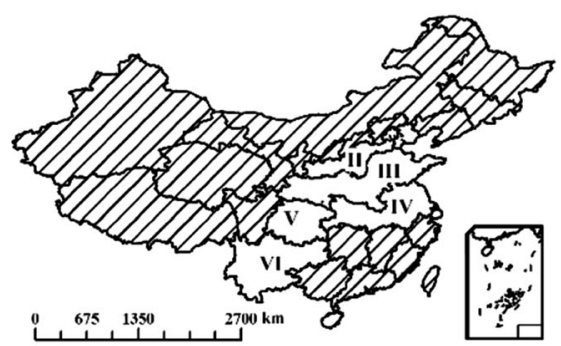

(c)

Fig. 1 Agricultural zoning maps of China. a Maize, b Rice, $\mathbf{c}$ Wheat

et al. 2009). Without adverse selection and moral hazards, weather index-based insurance (WII) has shown tremendous potential for replacing traditional crop insurance, since the World Bank implemented a Development Marketplace Contract and put WII into practice in Nicaragua, Morocco, Tunisia, and Ethiopia (Skees 2001, 2008; Stoppa and Hess 2003; Hess and Syroka 2005; Antón et al. 2013). Similarly, WII has been regarded as an ideal alternative for traditional insurance in China (Boyd et al. 2011). Considering the portfolio of different weather index types and hazard strike levels strongly affecting spatial diversification of risk (Okhrin et al. 2013), more specific research was conducted in several regions of China. For example, surveys in Shaanxi, Henan, Gansu, and Anhui Provinces showed Chinese farmers had great willingness to adopt weather indices, for example excessive heat degree days (Turvey and Kong 2010; Liu et al. 2010). There have also been pilot programs regarding weather indices, such as the late spring chilling and dry hot wind indices for winter wheat (Yang et al. 2013) and excessive heat degree days index for rice (Yang et al. 2015) in Anhui Province. Results of these programs showed that to some extent WII provided objective economic compensation.

However, there has been little systemic and comprehensive research on temperature-based index for the three main crops-maize, rice, and wheat-in China. Finding practical and reasonable indices that can capture weather fluctuations and be strongly correlated with crop yield losses is necessary and critically important for improving crop insurance operation (Stoppa and Hess 2003; Barnett and Mahul 2007; Elabed et al. 2013). Therefore, the present study focused on the following objectives: (1) to determine which temperature-based index could potentially be used at the county scale; (2) to characterize the spatial pattern of insurable counties and spatial relationship between different groups of insurable counties; and (3) to analyze correlation coefficients of insurable counties at different spatial scales. Furthermore, we address various findings concerning absolute and relative weather indices. The rest of the article is organized as follows. Section 2 introduces the data and methods. Section 3 presents the spatial distribution and correlation coefficients of insurable counties. Section 4 addresses differences between the selected indices and limitations of WII. Section 5 concludes our findings.

\section{Data and Methods}

This section introduced the study area and data sources. The correlation analysis between weather index and yield loss is then presented in detail. Standard deviation ellipse (SDE) is employed to quantify the spatial relationships of insurable counties.

\subsection{Study Area}

Base on the Chinese Landuse Dataset at $1 \mathrm{~km}$ resolution (Liu et al. 2003), counties in China where cultivated land covered more than $10 \%$ of the entire county area were selected for this study. The selected area covered more than $90 \%$ of the total cropping area in China for maize, rice, and wheat. Subzones for each crop are displayed in Fig. 1a (maize), b (rice) and $\mathrm{c}$ (wheat). Table 1 presents a description of the agricultural zones.

\subsection{Data Sources}

Meteorological data (1980-2008) were obtained from China Meteorological Administration (CMA) weather stations across the country, ${ }^{1}$ including daily average temperature $\left(T_{\text {mean }}\right)$, daily minimum temperature $\left(T_{\min }\right)$, and daily maximum temperature $\left(T_{\max }\right)$. Crop phenology records of about 270 agro-meteorological experimental stations across the major planting areas were also obtained from CMA. A county-level yield dataset (1980-2008) was furnished by the agricultural yearbook of each county (published annually by China Agriculture Press in Beijing), and some unpublished records were taken from local county census bureaus. The above data have been used in existing

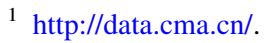


Table 1 Agricultural zones in China

\begin{tabular}{llllll}
\hline ID & Name & Acronym & Wheat & Rice & Maize \\
\hline I & Northeast China & Northeast & & Single cropping rice & Spring maize \\
II & Northern China & North & Wheat & & Spring maize \\
III & Huang-huai-hai Plain & Huang-Huai-Hai & Wheat & & Summer maize \\
IV & Middle-Lower Yangtze Plain & Yangtze Plain & Wheat & Single and double cropping rice \\
V & Sichuan Basin & Sichuan & Wheat & Single cropping rice & Spring maize \\
VI & Yunnan-Guizhou Plateau & YG Plateau & Wheat & Single cropping rice & Summer maize \\
VII & Southern China & South & & Double cropping rice & \\
\hline
\end{tabular}

Only winter wheat was considered in the study

Table 2 Temperature-related agricultural disaster index for the three main crops (maize, rice, and wheat) in China

\begin{tabular}{llll}
\hline Agro-meteorological disaster & Crop & Absolute index & Relative index \\
\hline Chilling injury & Maize & CF & CTD \\
& Rice & CGDD $-\infty$, lower & CF \\
Heat damage & Winter wheat & HGDD $_{\text {upper, } \infty}$ & HTD \\
& Maize & & \\
& Rice & Winter wheat & \\
\hline
\end{tabular}

The first character of each index represents the disaster type- $\mathrm{C}$ for chilling injury, $\mathrm{H}$ for heat damage

Table 3 Definition of indices for temperature-related agricultural disaster

\begin{tabular}{|c|c|c|}
\hline Index & Formula & Description \\
\hline$C T D$ and $H T D$ & $\sum\left(T_{\text {mean }}-10\right)-\bar{T}$ & $\begin{array}{l}\text { Taking } \bar{T} \text { as the } 29 \text {-year average of } \geq 10{ }^{\circ} \mathrm{C} \text { accumulated temperature } \\
\text { (1980-2008), the annual anomaly indicates insufficient or excessive active } \\
\text { heat accumulation in the growing season (Yan et al. 2011). Anomaly lower } \\
\text { than }-50{ }^{\circ} \mathrm{C} \text { is CTD and higher than } 50{ }^{\circ} \mathrm{C} \text { is HTD }\end{array}$ \\
\hline$C G D D_{-\infty, \text { lower }}$ & $\sum\left(T_{\text {lower }}-T_{\text {mean }}\right)$ & $\begin{array}{l}\text { Growing degree day in booting stage and heading-flowing stage (Lobell et al. } \\
\text { 2011; Wang et al. 2014). } T_{\text {lower }} \text { for each stage is shown in Table } 4 \text { (QX/T } \\
\text { 182-2013) }\end{array}$ \\
\hline$H G D D_{\text {upper }, \infty}$ & $\sum\left(T-T_{\text {upper }}\right)$ & $\begin{array}{l}\text { Accumulated temperature over } T_{\text {upper }} \text { in reproductive stages (GBT 21985-2008). } \\
T \text { is } T_{\text {mean }} \text { for wheat and filling stage of maize, and } T \text { is } T_{\max } \text { for rice and } \\
\text { anthesis stage of maize. More details are shown in Table } 5\end{array}$ \\
\hline$C F$ & $\sum T_{\min }$ & $\begin{array}{l}\text { In different growing periods, frost thresholds are indifferent, see Table } 6 \text { (QX/T } \\
88-2008)\end{array}$ \\
\hline
\end{tabular}

All acronyms, e.g., $T_{\text {mean }}$, are explained in Sects. 1 and 2.2

research and their validity tested (Liu et al. 2010; Wang et al. 2014; Zhang et al. 2016).

\subsection{Correlation of Weather Index and Yield Loss}

This section introduces the weather indices that are selected to measure chilling injury and heat damage for three main crops in the study area and the calculation of yield loss. Pearson $\mathrm{R}$ is employed as the correlation coefficient between weather index and yield loss.

\subsubsection{Weather Index}

Many weather indices for chilling injury and heat damage were introduced in previous studies (Ju et al. 1997; Alexander et al. 2006; CMA 2008, 2013; General Administration of Quality Supervision, Inspection and Quarantine of the People's Republic of China and Standardization Administration of the People's Republic of China 2008; Ma et al. 2008; Dong et al. 2009; Lobell et al. 2011; Wang et al. 2014). In this study, we chose three 
Table 4 Low temperature threshold for rice in different regions. Source CMA (2013)

\begin{tabular}{|c|c|c|}
\hline Region & Rice & Chilling temperature \\
\hline \multirow[t]{2}{*}{ Northeast } & 2 or more consecutive days in booting stage & $\leq 17{ }^{\circ} \mathrm{C}$ \\
\hline & 2 or more consecutive days in heading stage & $\leq 19^{\circ} \mathrm{C}$ \\
\hline \multirow[t]{2}{*}{ Yangtz Plain, Sichuan, YG Plateau, and South } & 2 or more consecutive days in booting stage & $\leq 17{ }^{\circ} \mathrm{C}$ \\
\hline & 3 or more consecutive days in heading stage & $\leq 22{ }^{\circ} \mathrm{C}$ \\
\hline
\end{tabular}

Table 5 High temperature threshold for key growth stages of maize, rice, and wheat. Source General Administration of Quality Supervision, Inspection and Quarantine of the People's Republic of China and Standardization Administration of the People's Republic of China (2008)

\begin{tabular}{llll}
\hline Crop & Maize & Rice & Wheat \\
\hline Heading stage & & $T_{\max } \geq 35^{\circ} \mathrm{C}$ for 3 or more consecutive days & \\
Anthesis stage & $T_{\max } \geq 35^{\circ} \mathrm{C}$ & $T_{\max } \geq 35^{\circ} \mathrm{C}$ for 3 or more consecutive days & $T_{\text {mean }} \geq 24^{\circ} \mathrm{C}$ \\
Filling stage & $T_{\text {mean }} \geq 25^{\circ} \mathrm{C}$ & $T_{\max } \geq 35^{\circ} \mathrm{C}$ & \\
\hline
\end{tabular}

Table 6 Frost threshold for key growth stages of maize and wheat. Source CMA (2008)

\begin{tabular}{llll}
\hline Crop & Seeding stage & Anthesis stage & Milky stage \\
\hline Maize & $<-1.0$ & $<0$ & $<-1.0$ \\
Wheat & $<-0.7$ & $<0$ & $<-1.0$ \\
\hline
\end{tabular}

absolute indices that represent extreme values during one unit of the crop growth period (Zhang et al. 2011): Chilling Growing Degree Days (CGDD) (Lobell et al. 2011; CMA 2013; Wang et al. 2014), Heat Growing Degree Days (HGDD) (General Administration of Quality Supervision, Inspection and Quarantine of the People's Republic of China and Standardization Administration of the People's Republic of China 2008; Lobell et al. 2011; Wang et al. 2014), and Frost (CF) (CMA 2008); and two relative indices, also known as annual anomaly, which refer to extreme values above or below the long-term average annual values (Klein Tank and Können 2003): Chilling Temperature Deviation (CTD) and Heat Temperature Deviation (HTD) (Yan et al. 2011) (Tables 2, 3). Both CGDD and CF were selected as chilling injury absolute index because for rice, only few areas in Northeast suffer from frost whereas CGDD is widely accepted as a chilling injury index for rice in the entire rice planting areas across the country. These indices are most widely used in agrometeorological research and are regarded as reasonable measurement of agro-meteorological hazards.

\subsubsection{Yield Loss}

Crop yield $(\mathrm{Y})$ consists of trend yield ( $Y_{\text {trend }}$, which is generally contributed by agricultural management, technology, policies, and others), climate yield ( $\left.Y_{\text {climate }}\right)$, and random errors ( $(\varepsilon)$ (Eq. 1) (Ju et al. 1997; Xue et al. 2003). Generally, $\varepsilon$ was small enough to be ignored. Based on this equation, we defined relative weather yield loss $\left(Y_{\text {loss }}\right)$ using Eq. 2.

$Y=Y_{\text {trend }}+Y_{\text {climate }}+\varepsilon$

$Y_{\text {loss }}=\frac{Y_{\text {climate }}}{Y_{\text {trend }}}=\frac{Y-Y_{\text {trend }}}{Y_{\text {trend }}}$

A weighted moving average filter was used to calculate $Y_{\text {trend }}$. The weight $C_{j-k+1}$ for 5 years is defined in Eq. 3 and $Y_{\text {trend }}$ in the $j$ th year is defined in Eq. 4 (Shi et al. 2008).

$C_{j-k+1}=\frac{(p-k+1)}{\sum_{k=1}^{p} k}$

$Y_{\text {trend }}^{j}=\sum_{k=1}^{p} C_{j-k+1} \times Y^{j-k+1}$

In this study, $j$ ranges from 1 to 29 (1980-2008). $p$ is the length of the moving window, and set to 5 according to prior research, therefore, $\mathrm{k}$ ranges from 1 to 5 in order to calculate weight value of each year in the moving window. $\mathrm{C}_{\mathrm{j}-\mathrm{k}+1}$ is the weight for each year in the moving window. The trend yield at the $j$ th year $Y_{\text {trend }}^{j}$ is regarded as the weighted sum in the moving window.

\subsubsection{Correlation Analysis}

Pearson coefficient $\mathrm{R}$ is an index that has been widely used to capture the effect of climate variables on yield (Martin et al. 2001; Vedenov and Barnett 2004; Porter and Semenov 2005; Lobell and Field 2007). Therefore, we used R to measure the correlation between yield loss and the weather index, both of which were tested by de-autocorrelation to assure reliability of the correlation analysis (Zhang et al. 2000; Wang and Swail 2001; Alexander et al. 2006; Moore and Lobell 2014). The confidence level of $\mathrm{R}$ was set to 


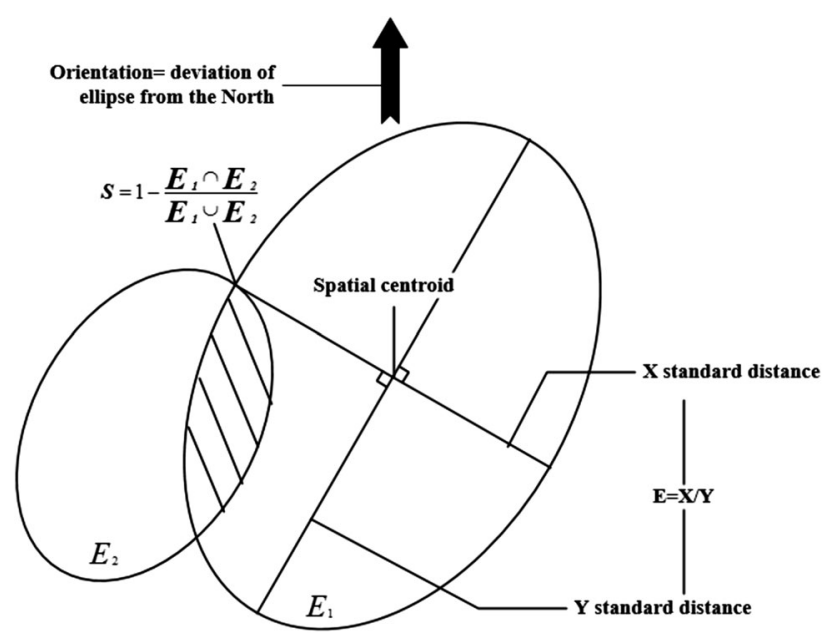

Fig. 2 Typical SDE and accompanying measures

$90 \%$ so that only a county with high significance was defined as an insurable county. Insurable counties were subsequently classified into different categories, including chilling injury-insurable, heat damage-insurable, and CTDinsurable.

\subsection{Spatial Analysis Using Standard Deviational Ellipse (SDE)}

Standard deviational ellipse (SDE) was introduced by Lefever (1926) and has been widely used in various geographic studies (Furfey 1927; Wong 1999; Gong 2002). The SDE can reflect the location, dispersion, and orientation of individual group of features, and is convenient for comparing different spatial patterns and relationships. The SDE was automatically calculated by ArcGIS 10.2 software at the regional scale in our study. More specifically, at least three insurable counties were needed in order to calculate a SDE, and the SDE centroid was calculated by averaging the coordinates of insurable counties. The coordinates of each county were then transformed into a metric space referenced from the centroid. In this space, the rotation angle and length of two axes were calculated (Wong 1999).

In analyzing the spatial dispersion of insurable counties, the eccentricity index $(E)$ indicates the SDE polarity. A smaller value of $E$ indicates a more polarized distribution, whereas a value close to 1 signifies a more uniform distribution (Johnson and Wilson 2009). To analyze the spatial relationship between SDEs of two categories of indices for the same hazard, the segregation index $(S)$ was defined. Generally, the value of $S$ ranges from 0 to 1 , indicating perfect overlap to spatial separation (Wong 1999; Gong 2002). For example, if the SDE of HTD-insurable counties is totally separated from that of HGDD-insurable counties,
$S=1$; but if the former overlaps with the latter, $S=0$. Figure 2 shows a typical SDE and the accompanying measures.

\section{Results}

We defined a county as an insurable county if the significance of correlation between its weather index and yield loss was $>0.9$. Insurable counties were classed into different categories, including chilling injury-insurable, heat damage-insurable, CTD-insurable, and so on. Counties where the length of time series for the absolute indices was $<10$ (Bonett and Wright 2000) were defined as unable to be calculated, because few disaster events were covered during the period. The correlation results are mapped and spatial distribution characteristics of insurable counties are analyzed in Sect. 3.1. Correlation coefficients of insurable counties are then assessed and compared in Sect. 3.2.

\subsection{Spatial Distribution of Insurable Counties}

Insurable counties are colored and those unable to be calculated are in gray in Fig. 3, 4 and 5, which represent maize, rice, and wheat, respectively. In these figures, chilling injury and heat damage are each measured by two types of indices according to Table 1 .

\subsubsection{Maize}

Heat damage-insurable counties covered $40.7 \%$ of the total planting area (Fig. 3b). Moreover, the ratio of HGDD-insurable counties (Fig. 3b-HGDD) was $28 \%$, while the ratio of HTD-insurable counties (Fig. 3b-HTD) was $15.8 \%$. Chilling injury-insurable counties covered much less area than heat damage-insurable counties. Chilling injury-insurable counties made up only $5 \%$ of the total area, and the number of CF- and CTD-insurable counties was 33 and 18, respectively, out of a total of 1000 counties. For both agrometeorological hazards, the absolute indices-insurable counties (Fig. 3a-CGDD, b-HGDD) were less than those of relative indices (Fig. 3a-CTD, b-HTD).

Spatially, the chilling injury-insurable counties were scattered in the Northeast, as CTD mainly covered peripheral areas and CF covered the central areas (Fig. 3a). The heat damage-insurable counties, as expected, were mainly in lower-latitude areas, including the North, HuangHuai-Hai, Yangtze Plain, Sichuan, and YG Plateau regions (Fig. 3b). Compared with most HGDD-insurable counties in North, the HTD-insurable counties were mainly in Huang-Huai-Hai.

According to the SDE, the most distinct polar distribution for heat damage was in western Huang-Huai-Hai 


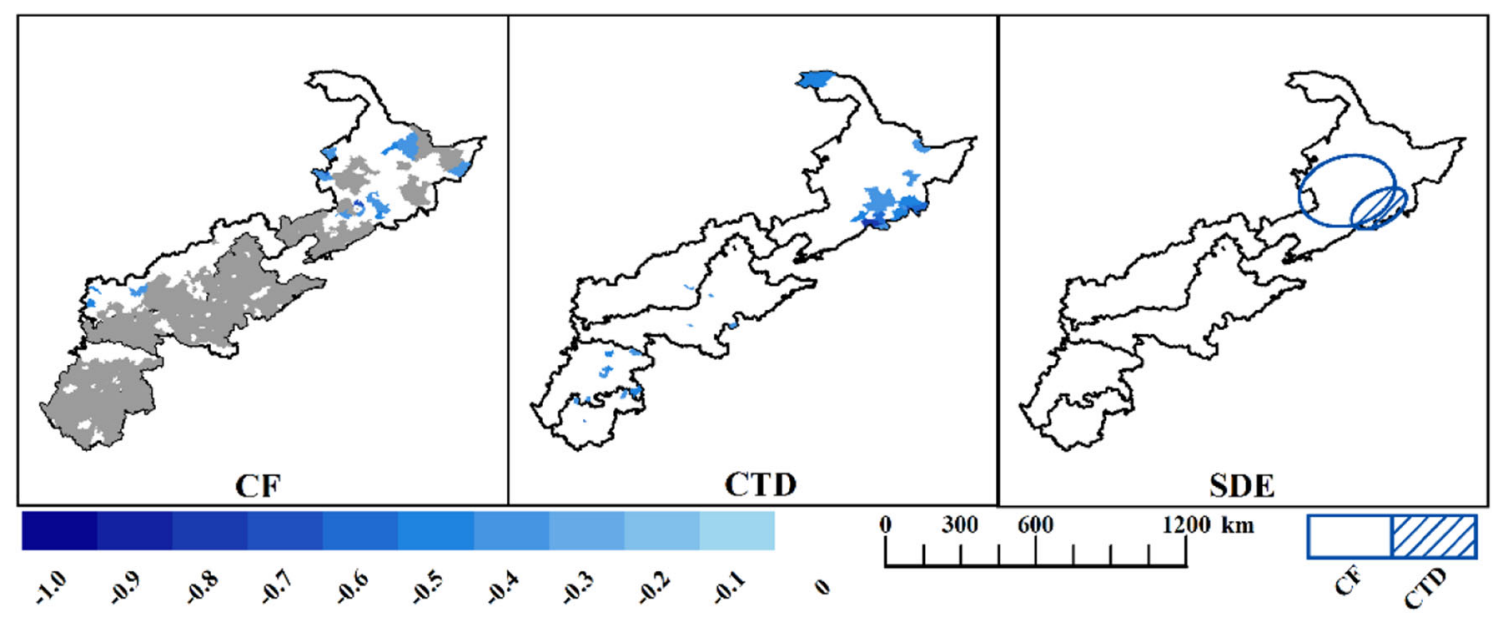

(a) Chilling Injury

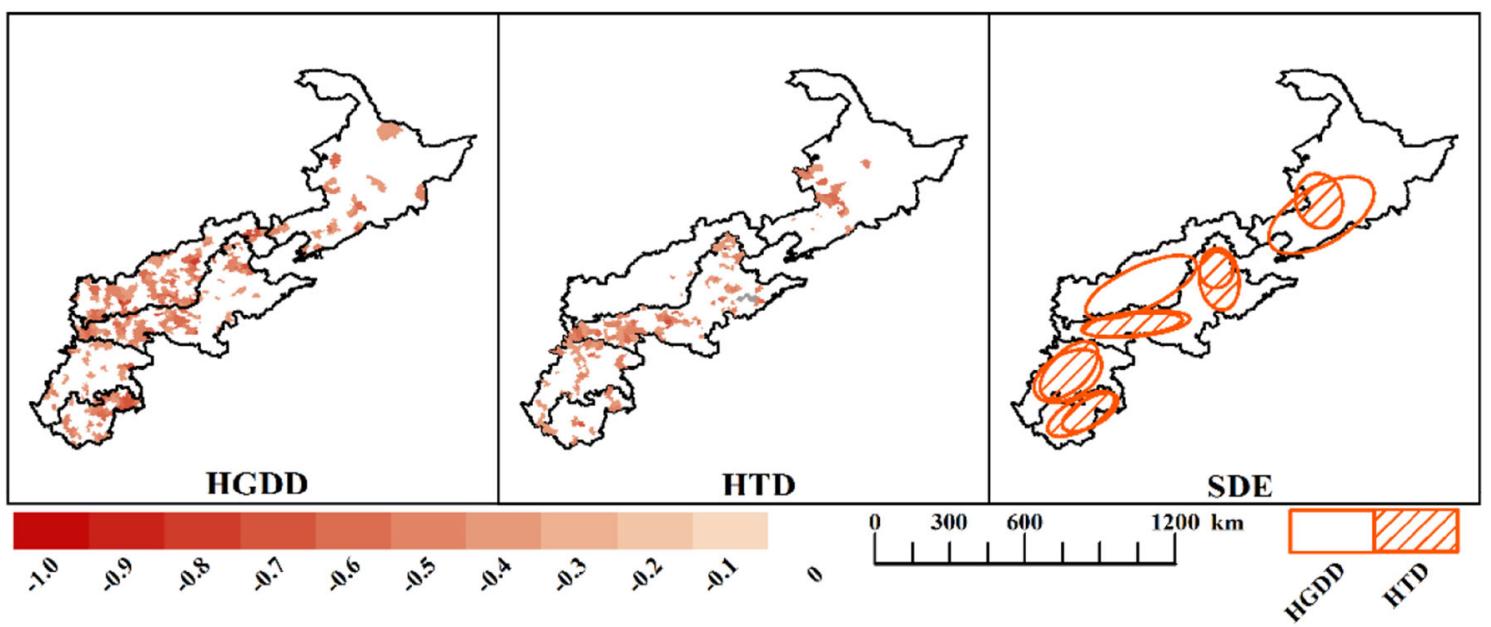

(b) Heat Damage

Fig. 3 Spatial distribution of insurable counties for chilling injury and heat damage of maize: a chilling injury; $\mathbf{b}$ heat damage; and c SDE. Open ellipses represent absolute weather indices and shaded

( $E=0.2$ for both HGDD and HTD, Fig. 3b-SDE), whereas the most uniform distribution was for HGDD in eastern Huang-Huai-Hai ( $E=0.9$, Fig. 3b-SDE). Orientations of the SDE consistently pointed northeast, except for HTD in Northeast and eastern Huang-Huai-Hai. The segregation of SDE pairs in North planting area was greater than in South. Almost perfect segregation was found in Northeast for chilling injury ( $S=0.9$, Fig. 3a-SDE), followed by heat damage ( $S=0.7$, Fig. 3b-SDE). For other SDE pairs, the absolute index SDE almost completely overlapped the relative index SDE, with weak segregation between them.

\subsubsection{Rice}

Heat damage-insurable and chilling injury-insurable counties both made up about $23 \%$ of the total planting area (1340 counties). Specifically, the absolute index-insurable ellipses relative weather indices. Negative values of $\mathrm{R}$ indicate disasters resulting in yield loss

counties for chilling injury (160, Fig. 4a-CGDD) were fewer than relative index-insurable counties (205, Fig. 4aCTD). However, heat damage showed an opposite resultthe absolute index-insurable counties (206, Fig. 4bHGDD) were more numerous than the relative index-insurable counties (167, Fig. 4b-HTD).

Spatially, there were more insurable countries in the Northeast region for chilling injury (Fig. 4a) than those for heat damage (Fig. 4b). However, the two agro-meteorological hazards did not show such major differences in other regions. With the aid of SDE, more details emerged for spatial distribution among various weather indices. Except for the HTD ellipse in the eastern YG Plateau (Fig. 4b-SDE), ellipses were oriented to the northeast, even due east (for example, the CTD ellipse in YG Plateau, Fig. 4a-SDE). The most polarized distribution of insurable counties was indicated by $E=0.3$ for CGDD in Northeast 


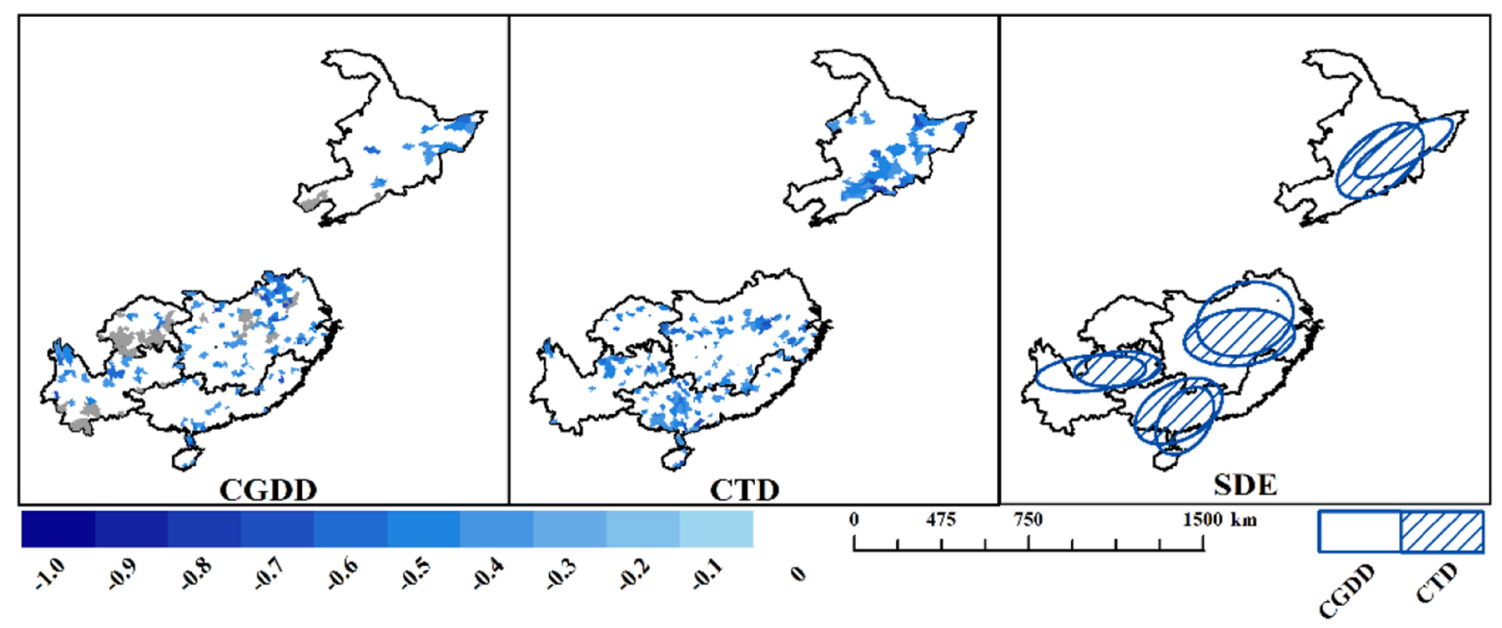

(a) Chilling Injury

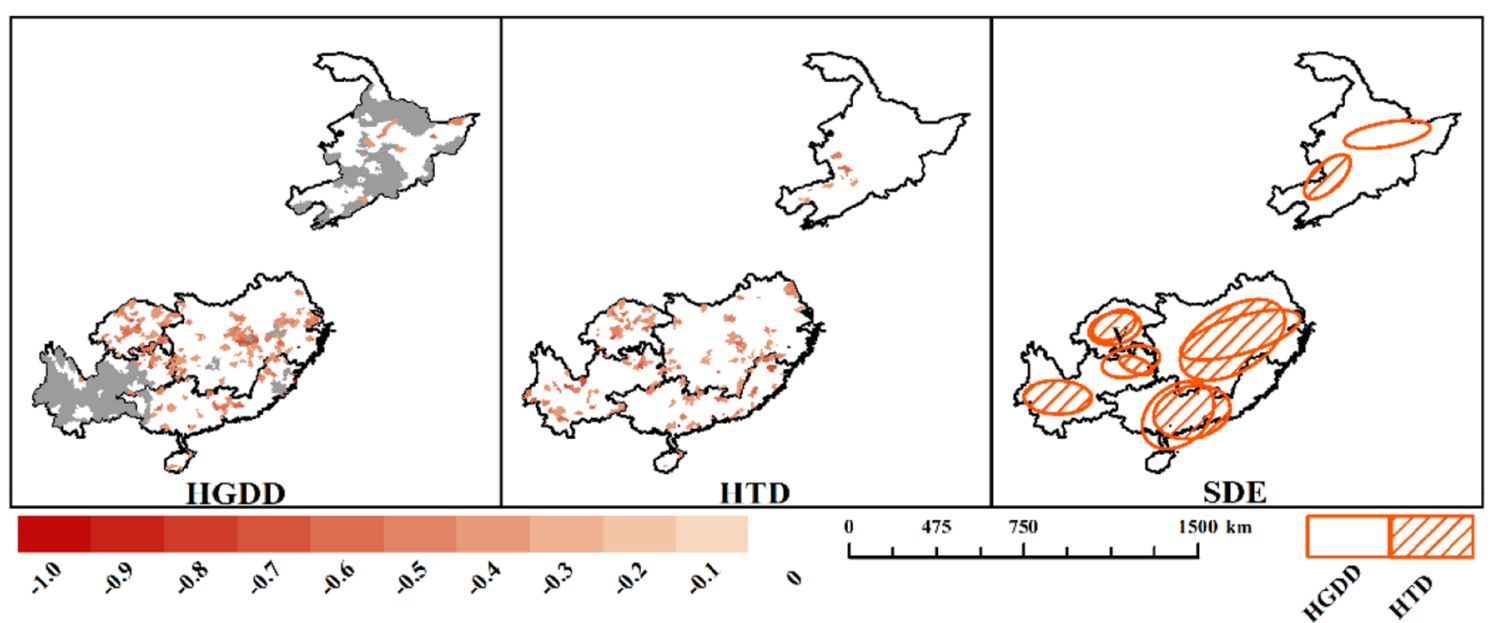

(b) Heat Damage

Fig. 4 Spatial distribution of insurable counties for chilling injury and heat damage of rice: a chilling injury; b heat damage; and $\mathbf{c}$ SDE. Open ellipses represent absolute weather indices and shaded ellipses

and YG Plateau regions (Fig. 4a-SDE) and HGDD in the Northeast and the Yangtze Plain (Fig. 4b-SDE). SDE pairs intersected with most segregation values $<0.6$ for chilling injury (Fig. 4a-SDE). However, for heat damage, relative index SDEs were completely overlapped by absolute index SDEs in most regions, except that SDE pairs were totally separated in Northeast ( $S=1$, Fig. 4b-SDE).

\subsubsection{Wheat}

For wheat, the number of chilling injury-insurable counties (217) was twice that of the heat damage-insurable counties (120) (Fig. 5a, b). Moreover, 105 counties were classified as CTD-insurable, fewer than CF-insurable counties (119) (Fig. 5a). The HTD-insurable and HGDD-insurable counties were 75 and 60, respectively (Fig. 5b). There were relative weather indices. Negative values of $\mathrm{R}$ indicate disasters resulting in yield loss

distinct spatial differences between chilling injury- and heat damage-insurable counties. Chilling injury-insurable counties were concentrated in the Yangtze Plain and YG Plateau regions (Fig. 5a), while heat damage-insurable areas were generally distributed in higher latitude areas of North and Sichuan (Fig. 5b).

The spatial distributions were further characterized by SDEs. For chilling injury, the relative index-insurable counties showed a nearly uniform distribution $(E=0.8)$ in Huang-Huai-Hai and Sichuan, while the absolute indexinsurable counties had a more polarized distribution and were oriented to the northeast ( $E=0.5$ in Huang-Huai-hai; $E=0.3$ on Yangtze Plain, $E=0.4$ on YG Plateau, Fig. 5a). For heat damage, orientations of SDEs were closely due east in North and Huang-Huai-Hai, with a polarized distribution $(E<0.4)$, while orientations were 
northeast in Sichuan, with less polarity $(E=0.6$ for HGDD, $E=0.4$ for HTD, Fig. 5b). As for SDE pairs, perfect SDE segregation ( $S=1$, Fig. 5a-SDE) was found for chilling injury in Huang-Huai-Hai and Yangtze Plain, closely followed by heat damage in Sichuan and HuangHuai-Hai ( $S=0.9$, Fig. 5b-SDE).

\subsection{Correlation Coefficients for Insurable Counties}

The above spatial analyses give a general view of the spatial patterns of weather indices of the three crops. However, information from the boxplot and kernel density estimator (Hintze and Nelson 1998) provides a more comprehensive assessment of weather indices. Magnitude and internal homogeneity of correlation coefficients (Pearson R) are generally accepted as two criteria for assessing data quality
Fig. 6 Probability distribution of correlation coefficient $R$ at the national and the regional scales for (a) chilling injury and $\mathbf{b}$ heat damage. Roman numbers on the left side of $y$ axes represent regional code (see Table 1). The $y$ axis represents Pearson $\mathrm{R}$ value and, on the $x$ axis, first character of each index represents hazard type (see Table 2). The odd column in each figure is for absolute index (CF, CGDD and HGDD), and the even column with color shading is for relative index (CTD and HTD). The central axis divides the boxplot (at left) and kernel density estimator (at right). For boxplots and kernel density estimator, the central bar is the median; the upper and lower bars are at quartiles. Whiskers in boxplots extend to 1.5 times the interquartile range

(Devore and Berk 2007). A higher median in the boxplot corresponds to greater regional correlation overall. Moreover, the narrower the interquartile range (IQR) and the shorter the whiskers, the more homogenous the regional insurable counties were, which also could be accompanied

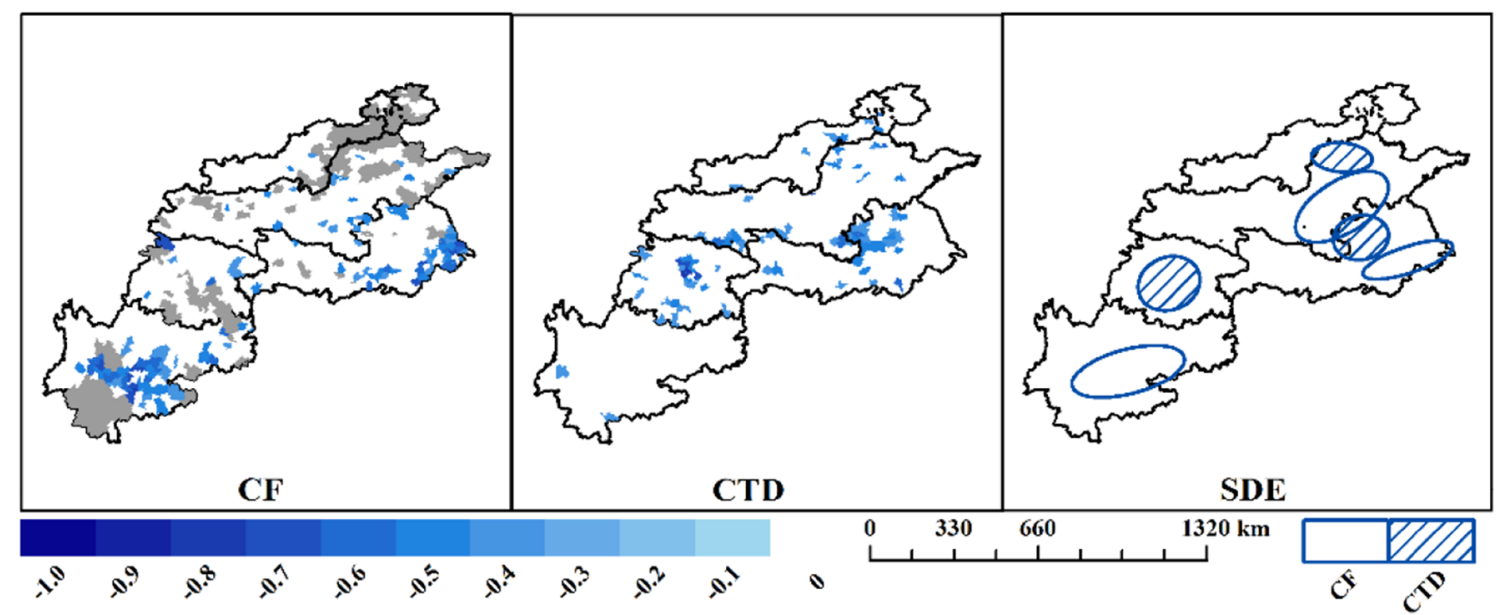

(a) Chilling Injury

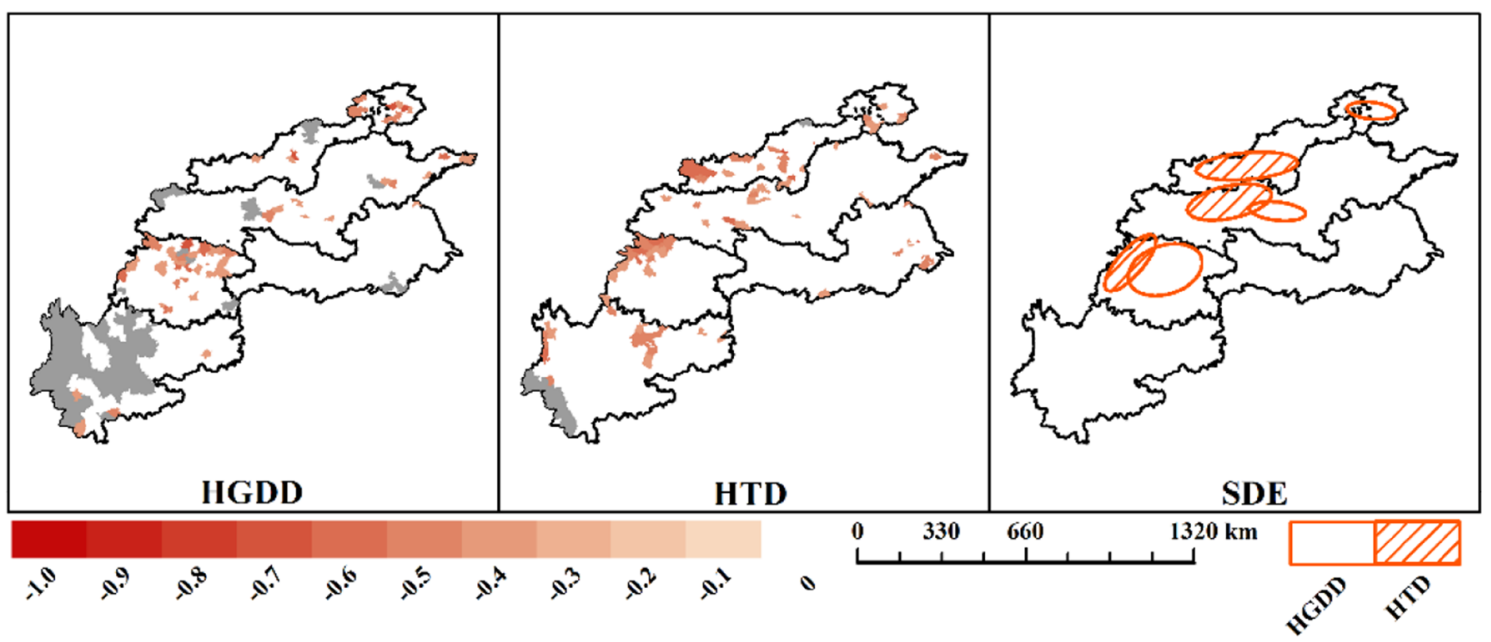

(b) Heat Damage

Fig. 5 Spatial distribution of insurable counties for chilling injury and heat damage of wheat: a chilling injury; b heat damage; and c SDE. Open ellipses represent absolute weather indices and shaded ellipses relative weather indices. Negative values of $\mathrm{R}$ indicate disasters resulting in yield loss 


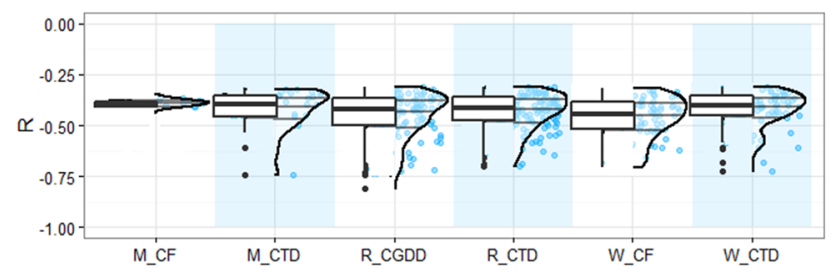

(a1) Chilling injury at the national scale

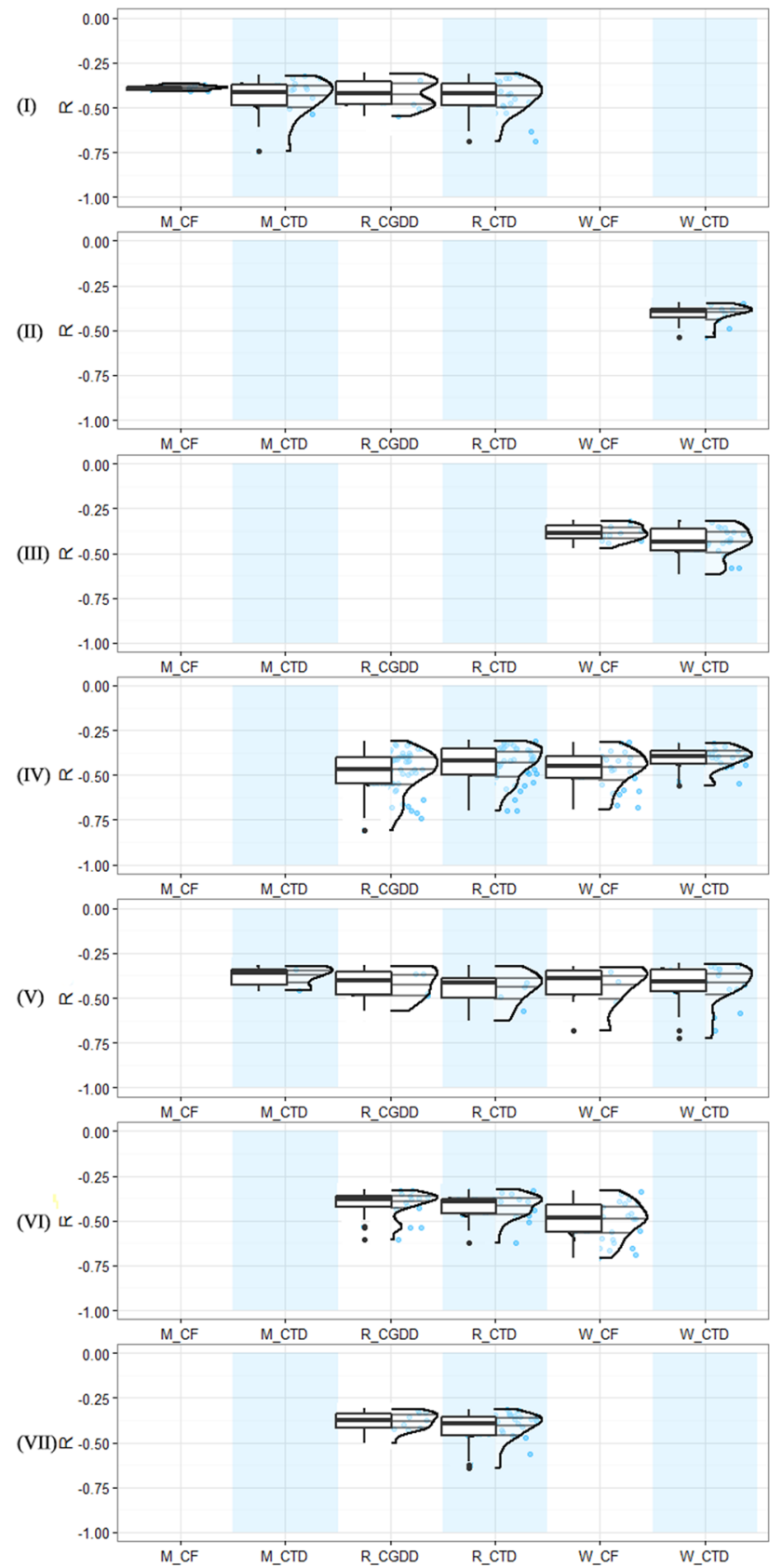

(a2) Chilling injury at the regional scale

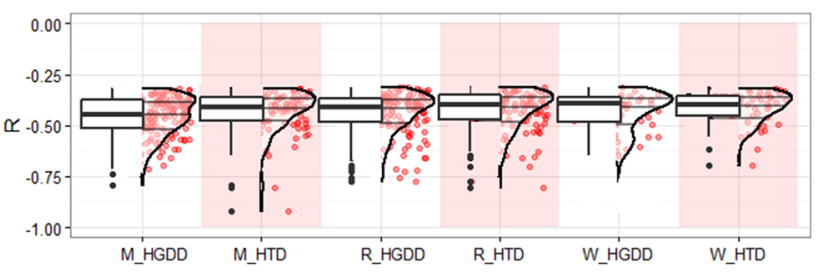

(b1) Heat damage at the national scale
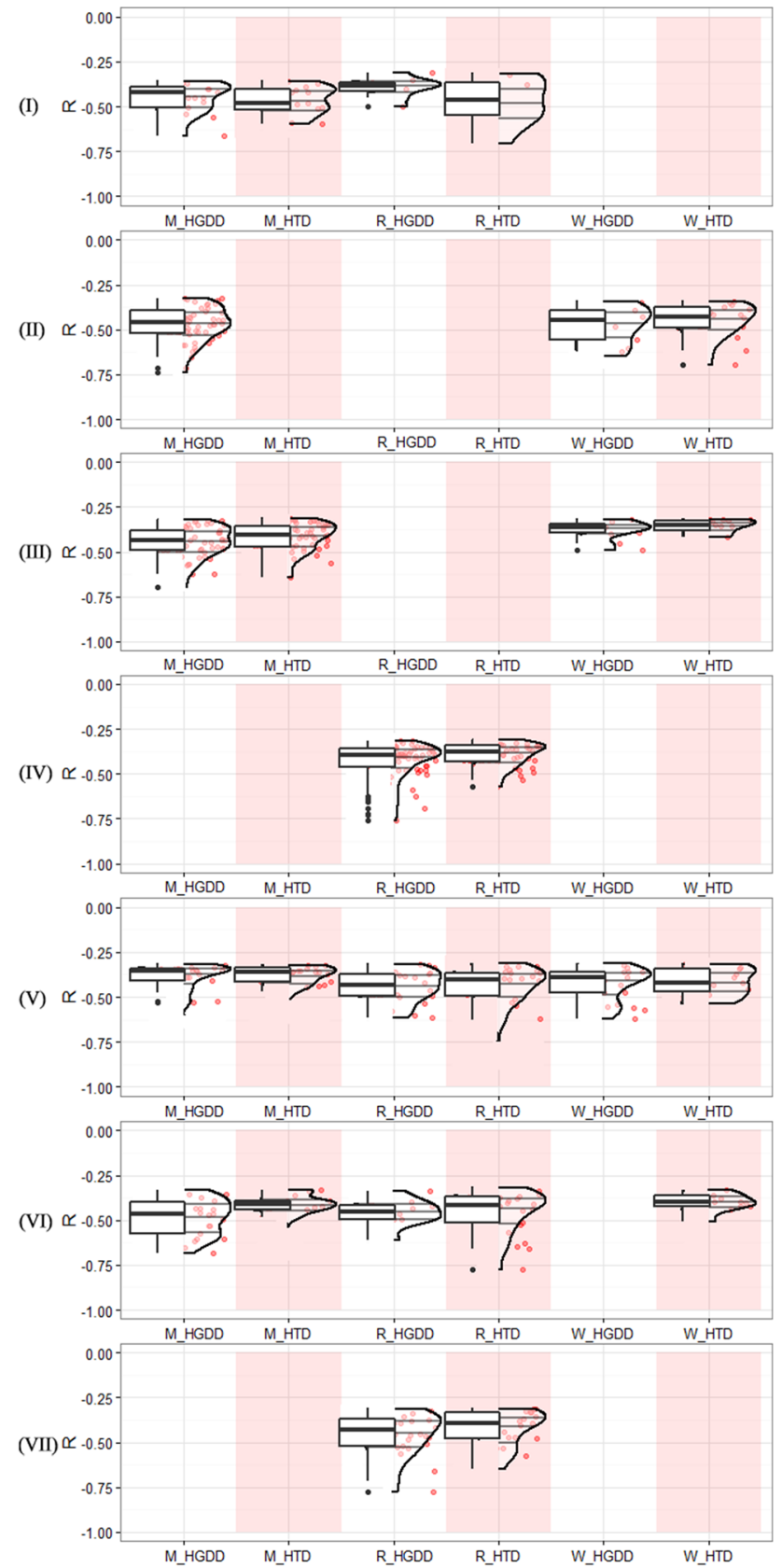

(b2) Heat damage at the regional scale 
by less outliers. Median, IQR, whisker, and outlier were used as indicators to evaluate different weather indices, with median as the main indicator.

According to the boxplots at the national scale, the strongest correlation $(-0.46)$ without any outlier was found for wheat frost index of chilling injury (Fig. 6a-1-W_CF). Similarly, maize HGDD best characterized heat damage $(-0.45)$, with only two outliers (Fig. 6b-1-M_HGDD). All kernel density estimators were consistently characterized by a skewed normal distribution at the national scale, with the exception of CF curves for maize (Fig. 6a-1-M_CF). Moreover, the national distribution curves show various types by regions, except $\mathrm{CF}$ for maize (Fig. 6a) with a normal distribution at both the national and the regional scales.

At the regional scale, the largest median of correlation coefficients for chilling injury was -0.42 in Northeast for maize (Fig. 6a-2-M_CTD), -0.47 in Yangtze Plain for rice (Fig. 6a-2-R_CGDD), and -0.49 in YG Plateau for wheat (Fig. 6a-2-W_CF). The strongest correlation for heat damage was -0.47 in Yangtze Plain for maize (Fig. 6b-2M_HGDD), -0.46 in Northeast for rice (Fig. 6b-2R_HTD), and -0.45 in North for wheat (Fig. 6b-2W_HGDD). All the largest medians mentioned above were consistently accompanied by the widest IQR, indicating poorer internal homogeneity.

For each region, correlation coefficients of weather index and yield loss were plotted in Fig. 6a-2, b-2. Odd columns show absolute index and even columns with color shading show relative index. For chilling injury (Fig. 6a-2), stronger correlation was indicated by the relative index values in most regions (for example, maize in Northeast, rice in Sichuan, YG Plateau, and South, and wheat in the Yangtze Plain and Sichuan regions). However, for heat damage (Fig. 6b-2), the absolute indices showed greater correlation than the relative indices in most regions (for example, maize in Northeast, Huang-Huai-Hai, and YG Plateau; rice in the Yangtze Plain, Sichuan, YG Plateau, and South regions; wheat in North and Huang-Huai-Hai).

The kernel density estimator was particularly useful for values that were close in the boxplots but indicated by different probability estimators. For example, in Sichuan, the coefficient boxplot of HTD for rice (Fig. 6b-2-R_HTD) was very similar to that of HGDD for wheat (Fig. 6b-2W_HGDD). However, we found that the kernel density estimator of the former had a skewed normal distribution, and a bimodal distribution characterizes the latter.

\section{Discussion}

Five weather indices, which were classified into absolute index and relative index, were analyzed at three spatial scales (county, regional, and national) in this study. The absolute indices were calculated using weather variables in current year, with a particular focus on reproductive stages of the crops, whereas relative indices were anomalies relative to the local average climatic conditions during the period 1980-2008. According to previous studies (Klein Tank and Können 2003; Zhang et al. 2011), an absolute annual weather index might be more suitable for assessing the impacts of extreme events. But the relative index might be best for evaluating changes in synoptic weather situations.

Consequently, we expected many differences between the two types of index. First, more counties were found unable to be calculated and were colored in gray in Figs. 3a_CF, 4a_CGDD, b_HGDD, 5a_CGDD, b_HGDD, because weather hazards measured by the absolute indices were fewer than these by the relative indices. Spatial relationship between different categories of insurable counties in the same region was then quantified by the SDE pairs. The absolute index-based insurable counties were totally separated from the relative index-based ones for wheat; the two categories of insurable counties intersected each other with nearly half being covered by both weather indices for rice; and almost all insurable counties overlapped each other for maize. Finally by further analyzing Pearson R of insurable counties, we found that the relative indices produced consistently larger correlation coefficients than the absolute indices for chilling injury, whereas there were larger coefficients of absolute indices for heat damage in most regions.

Various existing studies have identified many indicators for extreme weather events in the agricultural fields, including monthly minimum and maximum temperature, growing season length, warm days/nights, and cold days/ nights. But only more sophisticated indices such as those used in this study were applied in China for designing insurance products based on weather data. For example, farmers in Anhui Province received indemnity according to the frost index $(\mathrm{CF})$ for wheat and heat growing degree days index (HGDD) for rice, in which the insurance premium was calculated by the equilibrium option pricing methods (Yang et al. 2013, 2015). Similar indices, such as cumulative cooling degree days (CDDs) and heating degree days (HDDs) (Vedenov and Barnett 2004; Woodard and Garcia 2008; Norton et al. 2012), are also widely accepted by many researchers in other countries, but they have not been used as much in China.

Weather index is crucially important in WII and our research is the first systematic study focusing on temperature-related weather indices across the major planting areas of the three main crops-maize, rice, and wheat-in China. However, whether a potential weather index-based insurance product is practical depends on many factors. Basis risk is a systematic and primary problem in WII, 
which originates from geography and production. First, geographic basis risk arises from the distance between a reference weather station and farm locations, that is, climatic conditions are consistently different between farms and their reference weather station. Second, there is always a basis risk of production because yield loss is not perfectly correlated with a weather index (Skees 2008; Erec Heimfarth and Musshoff 2011). Thus, farmers may suffer yield loss but receive no compensation. Conversely, they may receive compensation without yield loss. Another unavoidable problem arising from index-based insurance programs is the low demand by target customers, mostly because poor farmers who can benefit most from such insurance are usually unwilling to purchase the smallest coverage (Binswanger-Mkhize 2012).

There have been various suggestions on how to solve the aforementioned problems. Norton et al. (2012) quantified and developed concepts on how to price spatial basis risk for WII. Elabed et al. (2013) analyzed a multi-scale index insurance contract to reduce basis risk. Other studies concentrated on the role of government and suggested that the government should not only establish an appropriate legal and regulatory framework (Barnett and Mahul 2007) but also provide more subsidies to crop insurance (Clarke et al. 2012; Skees 2011). Therefore, results of insurable counties could enable policymakers to make appropriate decisions, and policymakers also should take practical challenges into account by using more studies as reference.

\section{Conclusions}

Weather index-based insurance has been designed as a sustainable market mechanism to transfer risk in lower income countries for single peril crop insurance. In the present study, two categories of weather index for temperature-related hazards were examined to find insurable counties for three main crops in China. We found that not all counties were insurable, and results from the two index categories were not identical. Spatial distributions of insurable counties varied greatly according to different indices, but most were oriented northeast. Variable spatial relationships of SDE pairs were indicated for three crops, with strong segregation for wheat, less segregation for rice, and almost perfect overlap for maize. Further analysis of the correlation coefficients showed that stronger correlation was always accompanied by poorer internal homogeneity. The relative indices performed better than the absolute indices for chilling injury, whereas the absolute indices were better for heat damage.

Acknowledgements This study was supported by the National Natural Science Foundation of China (Project Number: 41571493,
41571088, and 31561143003) and the State Key Laboratory of Earth Surface Processes and Resource Ecology. We are grateful to reviewers and editors for their insightful comments on this article.

Open Access This article is distributed under the terms of the Creative Commons Attribution 4.0 International License (http://creative commons.org/licenses/by/4.0/), which permits unrestricted use, distribution, and reproduction in any medium, provided you give appropriate credit to the original author(s) and the source, provide a link to the Creative Commons license, and indicate if changes were made.

\section{References}

Alexander, L.V., X. Zhang, T.C. Peterson, J. Caesar, B. Gleason, A.M.G. Klein Tank, and A. Tagipour. 2006. Global observed changes in daily climate extremes of temperature and precipitation. Journal of Geophysical Research: Atmospheres. doi: 10. 1029/2005JD006290.

Antón, J., A. Cattaneo, S. Kimura, and J. Lankoski. 2013. Agricultural risk management policies under climate uncertainty. Global Environmental Change 23(6): 1726-1736.

Barnett, B.J., and O. Mahul. 2007. Weather index insurance for agriculture and rural areas in lower-income countries. American Journal of Agricultural Economics 89(5): 1241-1247.

Binswanger-Mkhize, H.P. 2012. Is there too much hype about indexbased agricultural insurance? Journal of Development Studies 48(2): 187-200.

Bonett, D.G., and T.A. Wright. 2000. Sample size requirements for estimating Pearson, Kendall and Spearman correlations. Psychometrika 65(1): 23-28.

Boyd, M., J. Pai, Z. Qiao, and W. Ke. 2011. Crop insurance principles and risk implications for China. Human and Ecological Risk Assessment 17(3): 554-565.

Challinor, A.J., T.R. Wheeler, P.Q. Craufurd, and J.M. Slingo. 2005. Simulation of the impact of high temperature stress on annual crop yields. Agricultural and Forest Meteorology 135(1): 180-189.

Chen, Y., Z. Zhang, P. Wang, X. Song, X. Wei, and F.L. Tao. 2016. Identifying the impact of multi-hazards on crop yield-a case for heat stress and dry stress on winter wheat yield in northern China. European Journal of Agronomy 73: 55-63.

CMA (China Meteorological Administration). 2008. QX/T 88-2008, Grade of crop frost damage. Beijing: China Standards Press (in Chinese).

CMA (China Meteorological Administration). 2013. QX/T 182-2013, Technical code for evaluation of rice chilling injury. Beijing: China Standards Press.

Clarke, D.J., D. Clarke, O. Mahul, K.N. Rao, and N. Verma. 2012. Weather based crop insurance in India. World Bank Policy Research Working Paper 5985. https://papers.ssrn.com/sol3/ papers.cfm?abstract_id=2016750. Accessed 15 Mar 2017.

Collier, B., J. Skees, and B. Barnett. 2009. Weather index insurance and climate change: Opportunities and challenges in lower income countries. The Geneva Papers on Risk and InsuranceIssues and Practice 34(3): 401-424.

Devore, J.L., and K.N. Berk. 2007. Modern mathematical statistics with applications. New York: Springer.

Dong, J., J. Liu, F.L. Tao, X. Xu, and J. Wang. 2009. Spatio-temporal changes in annual accumulated temperature in China and the effects on cropping systems, 1980s to 2000. Climate Research 40(1): 37-48 (in Chinese).

Elabed, G., M.F. Bellemare, M.R. Carter, and C. Guirkinger. 2013. Managing basis risk with multiscale index insurance. Agricultural Economics 44(4-5): 419-431. 
Erec Heimfarth, L., and O. Musshoff. 2011. Weather index-based insurances for farmers in the North China plain: An analysis of risk reduction potential and basis risk. Agricultural Finance Review 71(2): 218-239.

Furfey, P.H. 1927. A note on Lefever's "standard deviational ellipse". American Journal of Sociology 33(1): 94-98.

General Administration of Quality Supervision, Inspection and Quarantine of the People's Republic of China and Standardization Administration of the People's Republic of China. 2008. GB/T 21985-2008, Temperature index of high temperature harm for main crops. Beijing: China Standards Press (in Chinese).

Gong, J. 2002. Clarifying the standard deviational ellipse. Geographical Analysis 34(2): 155-167.

Hazell, P.B. 1992. The appropriate role of agricultural insurance in developing countries. Journal of International Development 4(6): 567-581.

Hess, U., and H. Syroka. 2005. Weather-based insurance in Southern Africa: The case of Malawi. Washington, DC: World Bank.

Hintze, J.L., and R.D. Nelson. 1998. Violin plots: A box plot-density trace synergism. The American Statistician 52(2): 181-184.

Johnson, D.P., and J.S. Wilson. 2009. The socio-spatial dynamics of extreme urban heat events: The case of heat-related deaths in Philadelphia. Applied Geography 29(3): 419-434.

Ju X.S., X.W. Yang, L.J. Chen, and Y.M. Wang. 1997. Research on determination of station indexes and division of regional flood/drought grades in China. Quarterly Journal of Applied Meteorology 1: 27-34 (in Chinese).

Klein Tank, A.M.G., and G.P. Können. 2003. Trends in indices of daily temperature and precipitation extremes in Europe, 1946-99. Journal of Climate 16(22): 3665-3680.

Lefever, D.W. 1926. Measuring geographic concentration by means of the standard deviational ellipse. American Journal of Sociology 32(1): 88-94.

Liu, B., M. Li, Y. Guo, and K. Shan. 2010. Analysis of the demand for weather index agricultural insurance on household level in Anhui, China. Agriculture and Agricultural Science Procedia 1: 179-186.

Liu, J.Y., D.F. Zhuang, D. Luo, and X.M Xiao. 2003. Land-cover classification of China: Integrated analysis of AVHRR imagery and geophysical data. International Journal of Remote Sensing 24(12): 2485-2500.

Lobell, D.B., and C.B. Field. 2007. Global scale climate-crop yield relationships and the impacts of recent warming. Environmental Research Letters 2(1): 014002. doi:10.1088/1748-9326/2/1/ 014002.

Lobell, D.B., M. Bänziger, C. Magorokosho, and B. Vivek. 2011. Nonlinear heat effects on African maize as evidenced by historical yield trials. Nature Climate Change 1(1): 42-45.

Martin, S.W., B.J. Barnett, and K.H. Coble. 2001. Developing and pricing precipitation insurance. Journal of Agricultural and Resource Economics 26(1): 261-274.

Ma S.Q., Q. Wang, C.Y. Wang, and Z.G. Huo. 2008. The risk division on climate and economic loss of maize chilling damage in Northeast China. Geographical Research 27(5): 1169-1177 (in Chinese).

Moore, F.C., and D.B. Lobell. 2014. Adaptation potential of European agriculture in response to climate change. Nature Climate Change 4(7): 610-614.

Norton, M.T, C. Turvey, and D. Osgood. 2012. Quantifying spatial basis risk for weather index insurance. The Journal of Risk Finance 14(1): 20-34.

Qian, B., X. Zhang, K. Chen, Y. Feng, and T. O'Brien. 2010. Observed long-term trends for agroclimatic conditions in Canada. Journal of Applied Meteorology and Climatology 49(4): 604-618.
Okhrin, O., M. Odening, and W. Xu. 2013. Systemic weather risk and crop insurance: The case of China. Journal of Risk and Insurance 80(2): 351-372.

Porter, J.R., and M.A. Semenov. 2005. Crop responses to climatic variation. Philosophical Transactions of the Royal Society of London B: Biological Sciences 360(1463): 2021-2035.

Ray, D.K., J.S. Gerber, G.K. MacDonald, and P.C. West. 2015. Climate variation explains a third of global crop yield variability. Nature Communications 6: Article 5989.

Shi, Y., Y. Wang, J. Chi, and R. Wei. 2008. Impact of Climate Change on Winter Production in the Hebei Plain. Chinese Journal of Eco-Agriculture 16(6): 1444-1447 (in Chinese).

Skees, J.R. 2001. Developing rainfall-based index insurance in Morocco. Research Working Paper 2577. Washington, DC: World Bank.

Skees, J.R. 2008. Challenges for use of index-based weather insurance in lower income countries. Agricultural Finance Review 68(1): 197-217.

Skees, J. 2011. Innovations in index insurance for the poor in lowincome countries. In Financial inclusion, innovation, and investments: Biotechnology and capital markets working for the poor, ed. R.D. Christy, and V.L. Bogan, 73-100. Hackensack, NJ: World Scientific Publishing Company.

Stoppa, A., and U. Hess. 2003. Design and use of weather derivatives in agricultural policies: The case of rainfall index insurance in Morocco. In Agricultural policy reform and the WTO: Where are we heading, ed. G. Anania, M.E. Bohman, C.A. Carter, and A.F. McCalla, 23-26. London: Edward Elgar Publishing.

Tao, F.L., M. Yokozawa, J. Liu, and Z. Zhang. 2008. Climate-crop yield relationships at provincial scales in China and the impacts of recent climate trends. Climate Research 38(1): 83-94.

Tao, F.L., S. Zhang, and Z. Zhang. 2013. Changes in rice disasters across China in recent decades and the meteorological and agronomic causes. Regional Environmental Change 13(4): 743-759.

Turvey, C.G., and R. Kong. 2010. Weather risk and the viability of weather insurance in China's Gansu, Shaanxi, and Henan provinces. China Agricultural Economic Review 2(1): 5-24.

Vedenov, D.V., and B.J. Barnett. 2004. Efficiency of weather derivatives as primary crop insurance instruments. Journal of Agricultural and Resource Economics 29(3): 387-403.

Wong, D.W. 1999. Geostatistics as measures of spatial segregation. Urban Geography 20(7): 635-647.

Wang, P., Z. Zhang, X. Song, Y. Chen, X. Wei, P.J. Shi, and F.L. Tao. 2014. Temperature variations and rice yields in China: Historical contributions and future trends. Climatic Change 124(4): $777-789$.

Wang, X.L., and V.R. Swail. 2001. Changes of extreme wave heights in Northern Hemisphere oceans and related atmospheric circulation regimes. Journal of Climate 14(10): 2204-2221.

Woodard, J.D., and P. Garcia. 2008. Basis risk and weather hedging effectiveness. Agricultural Finance Review 68(1): 99-117.

Xue, C., Z. Huo, S. Li, and C. Ye. 2003. Risk assessment of drought and yield losses of winter wheat in the northern part of North China. Journal of Natural Disasters 12(1): 131-139 (in Chinese).

Yan, M., X. Liu, W. Zhang, X. Li, and S. Liu. 2011. Spatio-temporal changes of $\geq 10{ }^{\circ} \mathrm{C}$ accumulated temperature in northeastern China since 1961. Chinese Geographical Science 21(1): 17-26.

Yang T.M., B.C. Liu, X.B. Sun, and S.P. Xun. 2013. Design and application of the weather indices of winter wheat planting insurance in Anhui Province. Chinese Journal of Agrometeorology 34(2): 229-235 (in Chinese).

Yang T.M., X.B. Sun, and B.C. Liu. 2015. Design on weather indices model for insurance of rice heat damage in Anhui Province. 
Chinese Journal of Agrometeorology 36(2): 220-226 (in Chinese).

Zhang, X., L.A. Vincent, W.D. Hogg, and A. Niitsoo. 2000. Temperature and precipitation trends in Canada during the 20th century. Atmosphere-Ocean 38(3): 395-429.

Zhang, X.B., L. Alexander, G.C. Hegerl, P. Jones, A.K. Tank, T.C. Peterson, B. Trewin, and F.W. Zwiers. 2011. Indices for monitoring changes in extremes based on daily temperature and precipitation data. Wiley Interdisciplinary Reviews: Climate Change 2(6): 851-870.

Zhang, Z., P. Wang, Y. Chen, S. Zhang, F.L. Tao, and X. Liu. 2014a. Spatial pattern and decadal change of agro-meteorological disasters in the main wheat production area of China during 1991-2009. Journal of Geographical Sciences 24(3): 387-396.

Zhang, Z., Y. Chen, P. Wang, S. Zhang, F.L. Tao, and X.F. Liu. 2014b. Spatial and temporal changes of agro-meteorological disasters affecting maize production in China since 1990. Natural Hazards 71(3): 2087-2100.

Zhang, Z., X. Song, F.L. Tao, S. Zhang, and W.J. Shi. 2016. Climate trends and crop production in China at county scale, 1980 to 2008. Theoretical and Applied Climatology 123(1-2): 291-302. 